\title{
A brief history of cortical functional localization and its relevance to neurosurgery
}

\author{
Zach Folzenlogen, MD, and D. Ryan Ormond, MD, PhD \\ Department of Neurosurgery, University of Colorado School of Medicine, Aurora, Colorado
}

\begin{abstract}
Modern cortical mapping is a cornerstone for safe supratentorial glioma resection in eloquent brain and allows maximal resection with improved functional outcomes. The unlocking of brain functionality through close observation and eventually via cortical stimulation has a fascinating history and was made possible by contributions from early physician-philosophers and neurosurgery's founding fathers. Without an understanding of brain function and functional localization, none of today's modern cortical mapping would be possible.
\end{abstract}

https://thejns.org/doi/abs/10.3171/2019.6.FOCUS19326

KEYWORDS cortical; language; localization; neurosurgery; functional; history

$\mathrm{C}$ ORTICAL localization was pioneered by early inquisitive neurosurgeons. Through meticulous observation and eventually cortical stimulation, they unlocked many functional regions of the brain. The variability among individual patients was also recognized, leading to the era of intraoperative functional mapping. With this understanding, lesion resection became safer and led to improved survival in our surgical patients.

\section{Early Theories on Brain Function}

Understanding the function of the brain and its functional arrangement had crude beginnings. The first theories localizing human intellect and experience were debated among the Greek natural philosophers, with two groups predominating. The cardiocentrists assigned the seat of consciousness to the heart and the encephalocentrists to the brain. The most famous of the cardiocentrists was Aristotle (384-322 BCE). Despite making significant contributions to the anatomical study of the brain, he taught that all sensory input was interpreted by the common sense, which resided within the heart. ${ }^{7}$ Aristotle described the brain as cold and bloodless, believing it to be thermo-regulatory in nature. ${ }^{20}$

Hippocrates of Kos (460-370 BCE), widely considered the father of medicine, was the first of the encephalocentrists. His works On Injuries of the Head and $\mathrm{On}$ the $\mathrm{Sa}$ - cred Disease laid the groundwork for understanding brain function and the beginnings of neurosurgical intervention. Herophilus of Chalcedon (335-280 BCE) and Erasistratus of Ceos (304-250 вСE) were pioneering Greek anatomists in Alexandria, Egypt, who made remarkable leaps in our understanding of motor and sensory nerves, the cranial nerves, and the origination of these nerves within the brain tissue itself. 48

Galen of Pergamon (129 to circa $216 \mathrm{CE}$ ), like the Hippocratics, was an encephalocentrist and served as physician to the gladiators in ancient Rome. Through human dissection (illegal in ancient Greece) and experimentation, Galen proved the brain to be the originator of movement and interpreter of sensation. He proposed the pneumatic theory of ventricular control, which assigned the cerebral ventricles as the modulator of consciousness. Through his observation of injured gladiators, he concluded that the severity of brain trauma was proportional to its proximity to the ventricular system and began our understanding of specific functional localization., ${ }^{1,2}$

Expanding on Galen's theories in the 4th and 5th centuries, Nemesius, the Bishop of Emesa, proposed the cell doctrine. In this theory, the ventricles were distinct chambers with distinct functions. The lateral ventricles were for perception of stimuli, the third ventricle was for analysis, and the fourth was for memory storage.$^{50}$ Still, little thought was given to the arrangement of the cortex itself. Evidence 
for this can be seen in the detailed anatomical woodcuts from medieval times. This includes the De Humani Corporis Fabrica, published in 1543 by Flemish anatomist Andreas Vesalius (1514-1564). Although he called cell doctrine into question, he offered no other solution and saw no active role for gray matter in mentation. This is evident in the inaccurate arrangement of gyri and sulci in his work (Fig. 1).$^{50}$ The cell doctrine would persist as a dominant theory for centuries. Increasing accuracy in cerebral cortical anatomy would be revealed in Cerebri Anatome in 1664. The work of Thomas Willis and his illustrator Christopher Wren, it was key in the movement toward emphasizing the cortex and not the ventricles as the seat of cognition. ${ }^{50}$ This important transition in thought and observation allowed for significant improvements in the understanding of brain function and functional localization.

\section{Anatomy as It Relates to Function}

In 1796, Franz Gall (1758-1828), a German neuroanatomist and physiologist, proposed the concept of phrenology. Phrenology taught that the brain was not a homogeneous unit, but instead an aggregate of mental organs with specific functions. These cerebral organs were topographically localized in the gyri and the relative size of each convolution was indicative of the strength of that particular faculty. Given that the skull ossifies over the brain during infant development, Gall proposed that the external surface of an individual's head could yield information on one's personality traits by diagnosing the internal state of the mental characters; i.e., that internal changes on the cortical surface would influence the skull and overlying skin and that these changes correlated with function (Fig. 2). ${ }^{15}$ Using a large number of patients to assess for specific personality traits and abilities, Gall was among the first to study not only deficits but also enhanced abilities in individuals in an attempt to better understand functional localization. Though phrenology was clearly wrong, the idea that function was localizable to specific regions of cortex was not, and through his work, he did make some interesting observations. For example, Gall was the first to declare that language production was centered in the frontal lobes after examining a wounded soldier in Napoleon's army. ${ }^{29}$ In later years, morphological asymmetries within the brain (not the skull) and their correlation to function would be confirmed. ${ }^{38,52}$

A staunch critic of phrenology, French physiologist and pioneer of anesthesia Jean P. Flourens (1794-1867) increased functional neuroscience knowledge through performing ablation. It is interesting to consider Flourens' attachment to vitalism (living beings have a distinct "vital principle" or "life force"), Christianity, and classical antiquity, and wonder how he ever became an initiator of a "modern" era in experimental neurophysiology. ${ }^{26}$ In particular, his criticism of phrenology was precisely because of Gall's claim that cerebral function was localizable. Flourens believed in what he termed "equipotentiality"that higher cerebral functions were more diffusely located. He tested his hypotheses by ablating peripheral nerves, the medulla oblongata, the quadrigeminal protuberance, the

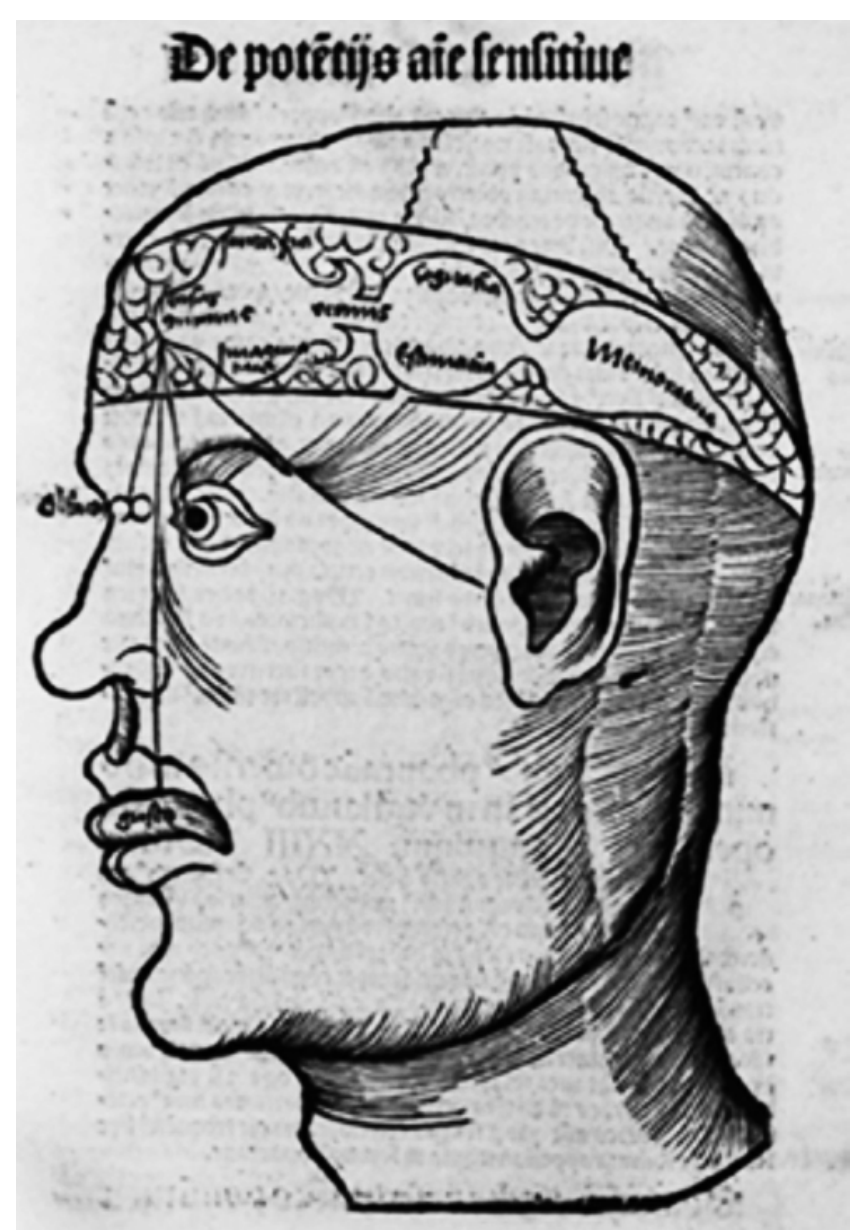

FIG. 1. In the 14th and 15th centuries, judgment, imagination, and memory were believed to reside in the ventricular system as can be seen from this diagram from the Margarita Philosophica. Reproduced from Reisch G: Margarita Philosophica cum additionibus nouis. Jo. Schottus, 1508. Public domain.

cerebellum, and the cerebral cortex of vertebrate animals, and then drew conclusions based on his observations. His methods allowed him to locate a respiratory center in the medulla oblongata and to localize motor coordination to the cerebellum. He also postulated that higher cognitive functions lay in the cerebral hemispheres. Due to an inability to exactly localize mental function and intellect, he declared that they were diffusely spread throughout the hemispheres and directly correlated with the volume of the brain tissue itself. ${ }^{15}$ Ultimately, Gall would be proven right, but "for the wrong reasons," whereas Flourens, on the other hand, would be "wrong for the 'right' reasons." 14,26 Thus, through the use of ablation, not skull shape, future research would prove cerebral localization correct (i.e., that specialized cortical regions have distinct functions).

As an alternative to ablation in humans, a number of physicians began studying the postmortem brains of patients with premorbid neurological deficits in order to better understand cortical localization. An example of this is French physician Jean-Baptiste Bouillaud (1796-1881), who contributed to cerebral localization with a specific fo- 


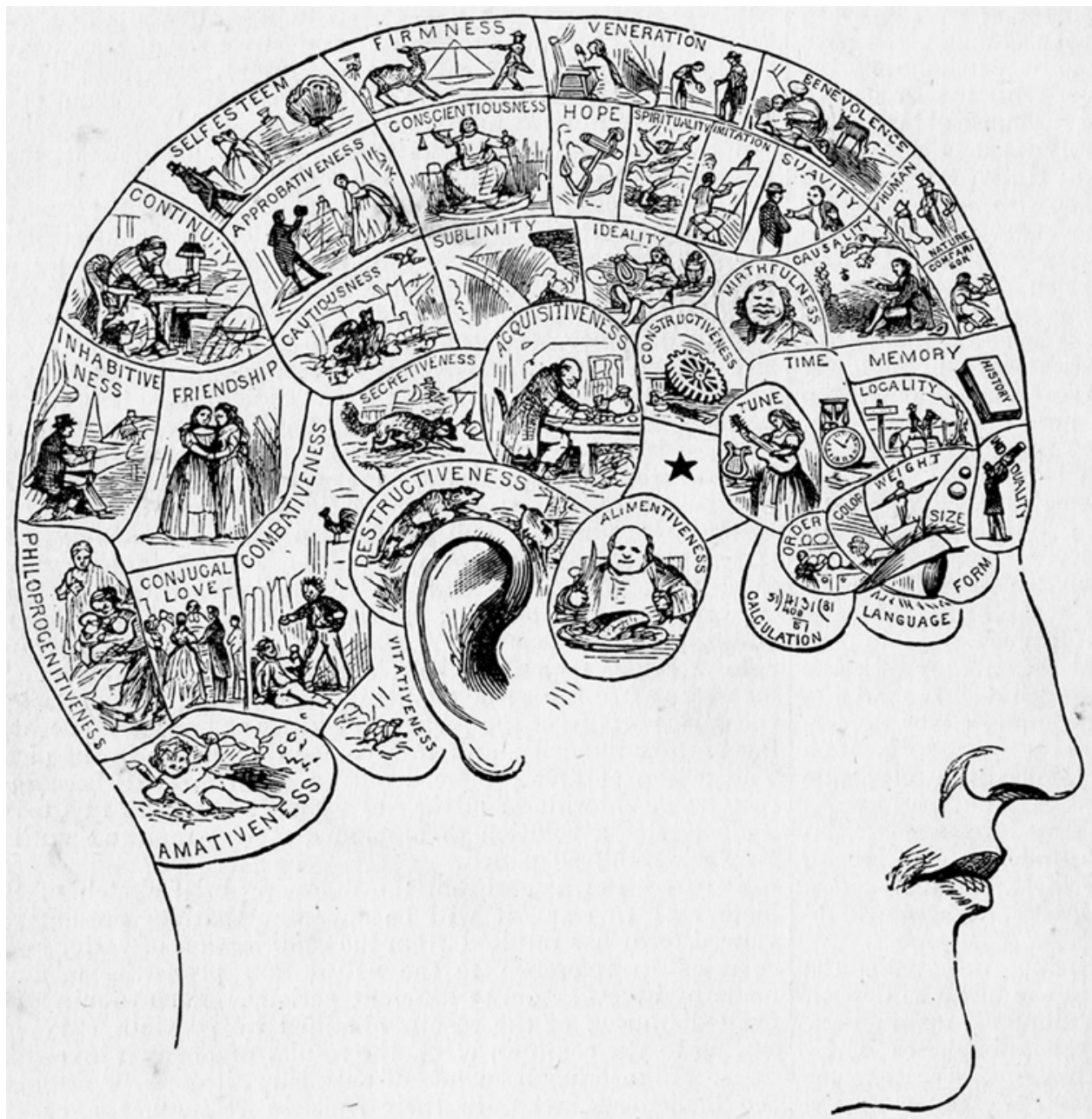

FIG. 2. In 1796, Franz Gall (1758-1828), a German neuroanatomist and physiologist, proposed the concept of phrenology. He believed the brain was not a homogeneous unit, but an aggregate of mental organs with specific functions that are topographically localized. Reproduced from De Puy WH: The People's Cyclopedia of Universal Knowledge. New York: Phillips \& Hunt, 1883. Public domain.

cus on speech centers. By performing postmortem analysis on patients harboring speech deficits, he concluded that language centers lay within the frontal lobes, but failed to recognize laterality or specific locations in those investigations. ${ }^{29}$ His son-in-law, Ernest Auburtin, while at a conference in Paris, met French physician Pierre Paul Broca (1824-1880). Working together, they located a lesion affecting the posterior third frontal convolution in the left hemisphere of a patient who died with an expressive aphasia. Naming of this regional cortex would forever pay tribute to its discoverer. ${ }^{5,6}$

French neurologist Joseph Jules Dejerine (1849-1917) and German physician Carl Wernicke (1848-1905) elaborated on other cortical locations associated with language and, together with contributions from others, developed the cortical connection theory. Through the clinical study of patients, they explored the posterior temporal convolution for understanding spoken language (Wernicke) and the angular gyrus for understanding written language (Dejerine). ${ }^{9}$ Along with other prominent names in the neuroscience community, they theorized that it was the combination of discrete cortical functional zones and their interconnectivity that made language and understanding language possible. These anatomical/pathological studies resulted in the classic view of language localization, still demonstrated in many textbooks today; i.e., expressive language in the frontal operculum and language perception in the posterior temporal lobe, with both connected via the arcuate fasciculus.

In addition to the study of patients with neurological deficits, the study of epilepsy yielded vast information on functional localization of the cerebral cortex. For a number of centuries since Thomas Willis proposed seizures originating from the thalamus in $1684,{ }^{51}$ the medical understanding of epileptogenesis had advanced very little, although an alternative hypothesis had been developed by the mid-1800s that epileptogenesis was instead centered in the medulla oblongata. It was in this controversial setting that Robert Bentley Todd began performing electrical stimulation experiments to induce seizures in animals. Through the course of these experiments, Todd developed his own hypothesis that epileptic seizures originated in the 
cerebral hemispheres where seizure activity caused loss of consciousness.$^{51} \mathrm{He}$ also noted that if the seizure activity continued into the mesencephalon, convulsions ensued, and if to the medulla, then convulsions took on a tonic character. ${ }^{12,51}$

It was during this period of significant change in the understanding of epileptogenesis and brain localization that John Hughlings Jackson (1835-1911) came on the scene. Often considered the father of modern neurology and epileptology, Jackson actually performed no experiments on animals or humans. Instead, he derived his many interpretations by "sustained meticulous observation" combined with taking into consideration the experimental findings of others (Eadie, 2009). ${ }^{12}$ One example of his observations was through his study of unilateral seizures, in which he concluded that motor movement was localizable to the cortex. ${ }^{42}$ His description of focal motor seizures was behind the coining of the term "jacksonian epilepsy." He also believed and described an evolutionary hierarchy within the nervous system. The higher levels, as in the cerebral cortex, exerted control over the lower ones, such as the diencephalon. By destroying a higher center, there was a negative symptom from its loss of function, but also a positive symptom from the loss of inhibition on a lower center. ${ }^{17,49}$

At this same time, Korbinian Brodmann (1868-1918) focused his career on the development of cytoarchitecture. Using cell-staining techniques developed by Carl Weigert (1845-1904) and Franz Nissl (1860-1919), he mapped the cortex based on cellular architecture into 52 separate locations. These regions were distinct with respect to their laminar organization. This was revealed in his 1909 work The Principles of Comparative Localization in the Cerebral Cortex Based on Cytoarchitectonics. Although he did not attribute specific functionality to these locations, as cortical functional localization became better understood, Brodmann's areas became quickly linked not only with cytoarchitecture, but with function as well. For example, Brodmann area 17 is also known as the visual cortex. Despite a difficult academic career, his work was the pinnacle in describing the unique cellular characteristics of cortex with differing functions. ${ }^{28}$

\section{Mapping the Brain Through Stimulation}

With the advent of sterile surgical technique and improvements in surgical technology (especially anesthesia), neurosurgical procedures became survivable. Surgeons could now develop techniques beyond trephination. In time, intraoperative functional assessment through stimulation would become essential to cortical preservation while maximizing neurosurgical resection of intrinsic masses.

Eduard Hitzig (1838-1907), a German neurologist in Berlin, reported experimentation with electrical currents in canine brains in $1870 .{ }^{4}$ During the Franco-Prussian War, where he cared for soldiers with head wounds, he observed their neurological deficits and performed postmortem analysis to confirm his findings from animal studies. ${ }^{23}$ In 1874, Roberts Bartholow (1831-1904), Professor of Medicine at the Medical College of Ohio, passed cur- rent through a patient's parietal skull defect and produced contralateral extremity muscle contractions. The skull defect was caused by a tumor. He would go on to defend his actions, concluding that although the tumor was the cause of the patient's demise, he would not repeat such experiments in the future. ${ }^{16}$

In 1885, the first resection of an intrinsic brain mass localized to the rolandic region was performed by Sir Rickman Godlee and John Hughes Bennett. ${ }^{27}$ Their ability to accurately turn a craniotomy was based on the mapping of animal cerebral cortex by David Ferrier. ${ }^{27}$ David Ferrier, inspired by physiologists such as Hitzig, worked alongside John Hughlings Jackson, one of the fathers of modern neurology and epileptology. Through animal experimentation, they confirmed that motor and sensory functions lay within the cortex surrounding the central sulcus and that there was very little interspecies variability to this organization. ${ }^{41}$ Ferrier and Jackson also experimented with localizing the auditory cortex, which they localized in the superior temporal gyrus. ${ }^{18}$

Early detailed maps of the motor cortex were based on experimental data from chimpanzees and orangutan models from Sir Victor Horsley (1857-1916) and others. ${ }^{19}$ Through stimulation, Horsley localized motor function to both pre- and post-rolandic fissure. Cortical mapping was later expanded by 1932 Nobel Prize recipient Charles Sherrington (1857-1952) by cortical stimulation in great apes. Using a monopolar electrode, he and Harvey Cushing (1869-1939) localized motor function exclusively anterior to the rolandic fissure with sensory function posterior. ${ }^{36}$ Horsley would argue over this for many years, insisting that motor function was both pre- and post-rolandic fissure. ${ }^{19}$ Cushing credits Sherrington for teaching all he knew about cortical stimulation, a technique he would apply in his surgical theater. In return, Cushing provided Sherrington with detailed illustrations, from which they reported their studies.

Between 1902 and 1912, while at Johns Hopkins Hospital, Cushing expanded mapping to the human motor cortex by using faradic stimulation..$^{36} \mathrm{He}$ completed motor mapping on 41 anesthetized patients with epilepsy, tumor, or trauma. A man before his time, operative records show he even examined subcortical pathways that produced similar responses to cortical stimulation. In an unanesthetized patient, Cushing mapped the sensorimotor distribution in 1908 (Fig. 3). Upon leaving Johns Hopkins for Brigham Hospital, he discontinued his cortical stimulation experiments to focus on other areas, but this important work continued under an able apprentice and friend, Wilder Penfield (1891-1976). ${ }^{25}$

Penfield was inspired by the work of Jackson and made many observations on brain function through the study of epilepsy and epilepsy surgery. His work was critical to developing our understanding of epileptogenic foci and its surgical treatment. Penfield traveled extensively during his early career to work with the likes of Santiago Ramón y Cajal and Otfrid Foerster (1873-1941), from whom he learned techniques for staining scarred brain and stimulating cortex. Using stimulation, in post-World War I Germany Foerster identified motor and sensory cortex to guide excision in a patient with posttraumatic epilepsy. 


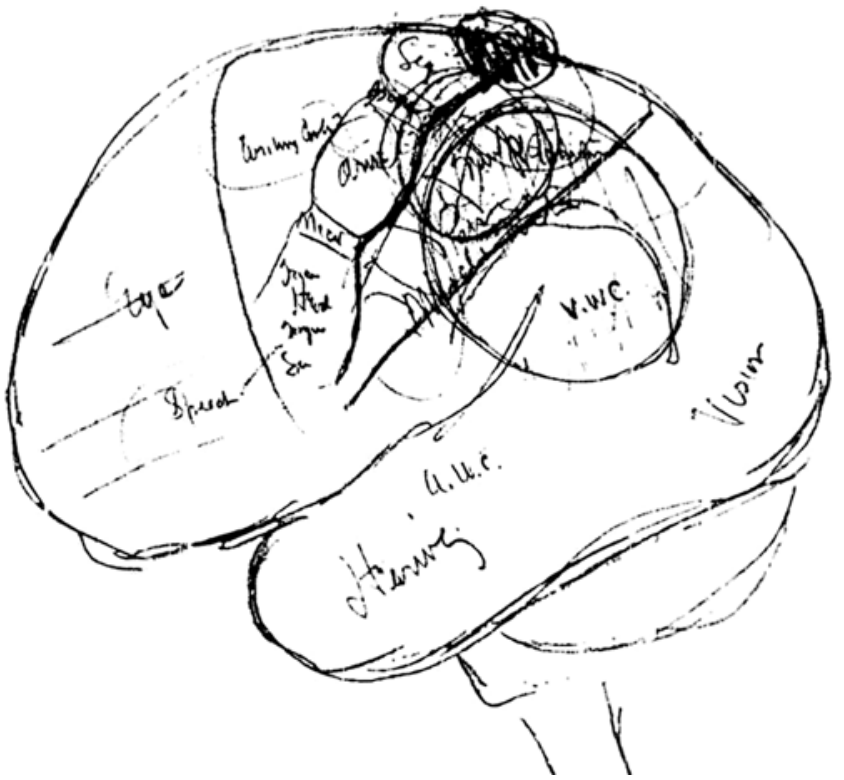

FIG. 3. Sketch by Harvey Cushing (1869-1939) where he labeled the areas in the frontal lobe responsible for eye movement and speech, as well as the temporal area responsible for hearing, and the occipital area where vision was located, in addition to perirolandic motor and sensory function. Courtesy of The Alan Mason Chesney Medical Archives. Public domain.
Penfield would spend 6 months learning from Foerster, and in that time they developed techniques for identifying seizure foci through stimulation with subsequent resection of the scarred tissue. This would be termed the FoersterPenfield technique. ${ }^{24}$

As founder and director of the Montreal Neurological Institute in 1934, Penfield pioneered the surgical treatment of epilepsy. He reported the first case of epidural EEG monitoring in 1939. Penfield also developed modern awake neurosurgery in which local anesthesia was used, dubbed the Montreal procedure. ${ }^{24}$

Over several years, Penfield performed cortical stimulation studies in 163 patients who were undergoing surgery for epilepsy. Through meticulous observation and recording, these studies were used to developed detailed functional maps of motor, sensory, speech, auditory, visu$\mathrm{al}$, and memory function. ${ }^{24}$ Penfield rendered the famous "homunculus" figure based on these findings (Fig. 4). By direct stimulation of the lateral temporal region, Penfield's patients experienced a flashback state in which they relived earlier experiences. He described this area as the "interpretive cortex."17 Among other important findings, these also have modern implications in the understanding of posttraumatic stress disorder. ${ }^{13}$ Penfield also began experimental stimulation of language centers. In 1959 Penfield and Lamar Roberts reviewed language manipulation in 110 patients in whom they recorded 132 aphasic-like errors. ${ }^{37}$ Based on the type of language error, they then mapped the classic functional zones of the language cortex.

The discrete locations identified in the early 20th cen-
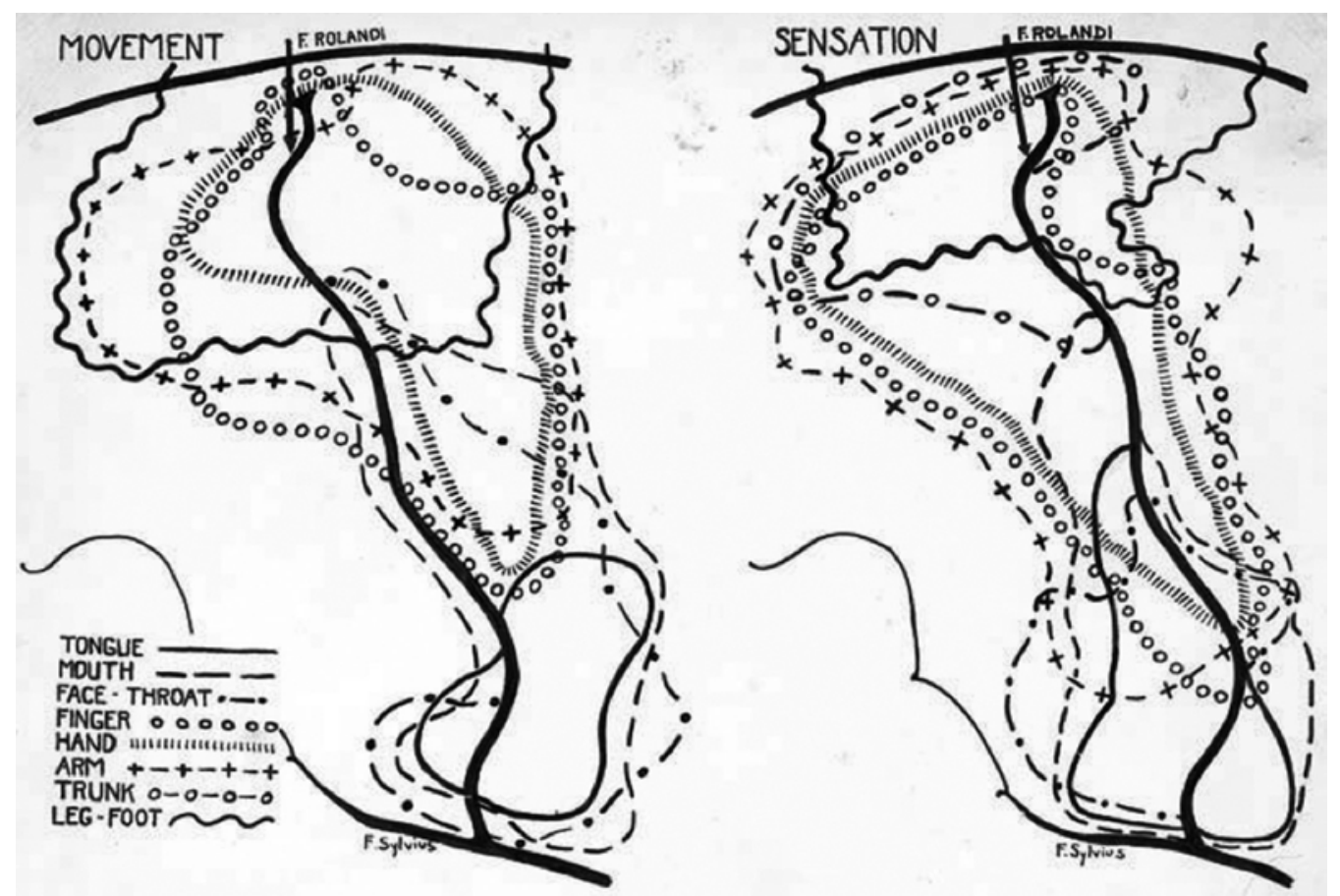

FIG. 4. Wilder Penfield reported on motor and sensory homunculi based on 126 patients. This picture shows a wide variability of sensation and motor function mapped to both the pre- and postcentral gyrus. Reproduced from Penfield W, Boldrey E: Somatic Motor and Sensory Representation in the Cerebral Cortex of Man as Studied by Electrical Stimulation. Brain, 1937, 60(4):389_ 443, by permission of Oxford University Press. 


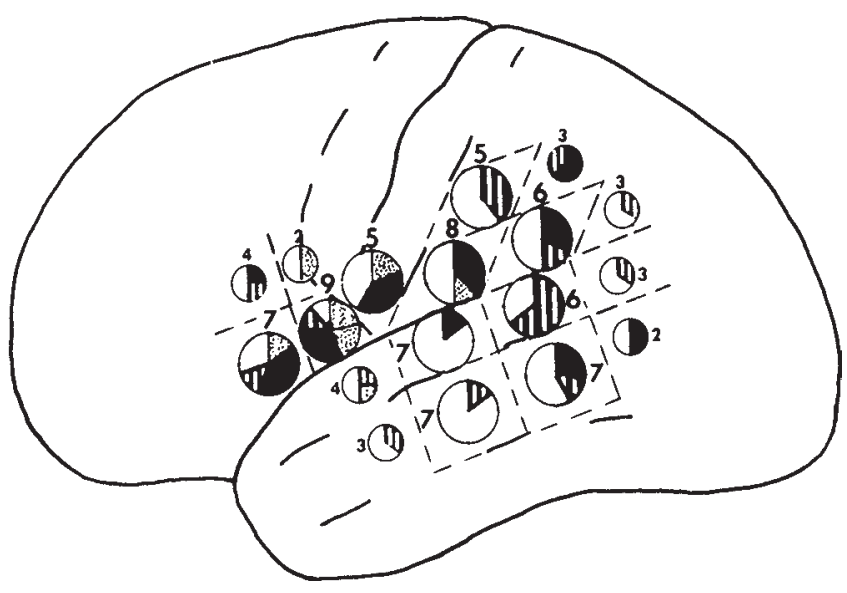

FIG. 5. Dr. Ojemann's work on language mapping showed the high degree of variability among individuals. This picture from his initial 1979 work on 10 patients shows the percentage of no naming errors, anomia, and speech arrest for various locations in the left hemisphere. Reproduced with permission from Ojemann GA: Individual variability in cortical localization of language. J Neurosurg 50:164-169, 1979. C AANS.

tury remained central to the teachings of brain function with respect to language. Many more physicians from around the world would contribute to this understanding in the ensuing years. Diagrams depicting the language system described during this time persist in textbooks today. Over the latter half of the 20th century, language would become one of the most widely studied functions of the brain.

\section{Modern Cortical Stimulation and Its Effects on Glioma Surgery}

The variability of language localization had been questioned since the late 19th century when Edward C. Seguin (1843-1898), an American neurologist, compiled literature from 52 autopsies of patients with aphasia and intracranial lesions. ${ }^{8}$ Two-thirds of these lesions were found to be outside of Broca's area. Early stimulation studies relied on pooled data from many patients to derive classic language locations (the posterior third of the third frontal convolution, the posterior half of the temporal lobe and adjacent inferior parietal lobe, and supplementary motor cortex of the face) but did little to determine differences among individual patients. Along with Seguin, others began to question the dogma of language localization.

In 1977, George Ojemann and Harry Whitaker explored language variability by stimulating a large number of locations (5-28) in 11 patients (9 left dominant, 1 right dominant, and 1 undetermined by Wada testing) undergoing elective surgery for psychomotor seizures. These authors' findings would show a much wider and larger distribution of function that was highly variable between patients (Fig. 5). ${ }^{33}$ Ojemann's findings would be especially true in the pathological brain, where he postulated that reorganization of language function may occur. These results were expanded with follow-up studies, the largest of which included 117 patients undergoing epileptic focus resection. ${ }^{32,33}$ Variability was again confirmed and a gradation between cortex essential to naming and cortex with no role was observed. The areas that greatly affected speech were found over a larger cortical area but the foci themselves were smaller than previously thought. Over time, with contributions from many individuals, it became clear that the language centers of the human cortex were not as simple as the initial schematics developed by early investigators. Although there are certainly discrete centers essential for language function, individualized wide distributions of neurons exist in the perisylvian structures. The discovery that language centers were highly variable meant that a seizure focus in the left temporal lobe was not necessarily unresectable from a functional standpoint. More aggressive and effective treatment could be delivered while maximizing functional outcomes in patients with seizure foci. These findings were equally applicable to cortical resection of tumors and vascular malformations.

In glioma surgery, methods for minimizing postoperative neurological impact while maximizing the total resection achieved have been shown to improve both the

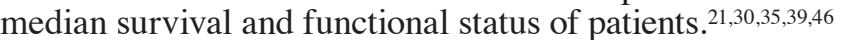
The Karnofsky score, a measure of residual function, has also been directly correlated with survival in patients with glioma. Invasive gliomas infiltrate normal, functioning tissue and cause changes in cortical topography due to mass effect and neural plasticity. Using stimulation, functioning tissue has been found within grossly abnormal tissue infiltrated by tumor-including essential cortex related to language and movement. ${ }^{34,45}$ Cortical reorganization/recruitment has been reported in patients recovering from stroke, those with seizure foci, and those with brain tumors. ${ }^{44}$

Intraoperative cortical stimulation has also been effective in seizure focus resection near eloquent cortex. Prior to Dr. Ojemann's work, cortical resection of foci near or in eloquent cortex was avoided. Techniques such as multiple subpial transection, proposed by Morrell and colleagues in 1989, were performed. ${ }^{31}$ Although widely used, the efficacy of multiple subpial transection has been questioned in several studies and is now considered palliative in nature or is performed in combination with resections. ${ }^{3,35,43,47}$ Often guided by preresection electrical stimulation mapping with subdural electrodes, cortical mapping has been shown to provide meaningful benefit while limiting deficits when removing seizure foci from eloquent cortex. ${ }^{11}$

Our armamentarium for functional understanding is growing and leading to improvements in resection outcomes for glioma surgery..$^{10,22,40}$ In 2008, Sanai et al. reported on 250 patients who underwent language mapping during glioma resection. Instead of larger craniotomies and the identification of positive language sites, smaller craniotomies were used. Stimulation was applied, and if speech was not affected, the area was determined safe for resection. Although transient deficits were noted, only 4 of the 243 patients who underwent craniotomy had a persistent new deficit. ${ }^{40}$ This study again concluded that language organization is highly variable and that real-time analysis is essential when resecting eloquent lesions.

A literature review from 90 studies (1990-2010) representing 8091 adult patients undergoing resective surgery for supratentorial glioma showed that late neurological deficits ( $>3$ months postsurgery) were less likely when using intraoperative cortical stimulation and that gross-total 
resection was more often achieved. ${ }^{10}$ The rate of late neurological deficits was twice as high in patients with resection in whom cortical mapping was not used, even though all patients in the mapping group had lesions that involved eloquent locations. These data supported the universal implementation of cortical and subcortical stimulation for resections near eloquent brain.

\section{Conclusions}

Understanding of the brain and its functional topography has a fascinating story written by bold and inquisitive neuroscientists over hundreds of years. In the modern era, the work of many neurosurgeons has specifically guided our current methods for operating in and around eloquent tissue. Intraoperative cortical stimulation, in combination with preoperative imaging analysis, has maximized resection while preserving functional tissue and improving outcomes. Cortical stimulation has now taken on even wider therapeutic value with the advent of neurostimulators for degenerative disease and functional restoration. As we dive deeper into understanding brain localization, it remains important that we reflect on those who came before us and the tremendous insight and advancements they provided, and that we look forward to a future of additional experimentation and collaboration to make surgery safer and more efficacious through improved brain functional localization.

\section{References}

1. Adams ZM, Fins JJ: Penfield's ceiling: Seeing brain injury through Galen's eyes. Neurology 89:854-858, 2017

2. Baig MN, Chishty F, Immesoete P, Karas CS: The Eastern heart and Galen's ventricle: a historical review of the purpose of the brain. Neurosurg Focus 23(1):E3, 2007

3. Blount JP, Langburt W, Otsubo H, Chitok u S, Ochi A, Weiss S, et al: Multiple subpial transections in the treatment of pediatric epilepsy. J Neurosurg 100 (2 Suppl Pediatrics):118-124, 2004

4. Breathnach CS: Eduard Hitzig, neurophysiologist and psychiatrist. Hist Psychiatry 3:329-338, 1992

5. Broca P: Localisations des fonctions cérébrales. Siège de la faculté du langage articulé. Bull Soc Anthropol Paris 4:200-204, 1863

6. Broca P: Perte de la parole, ramollissement chronique et destruction partielle du lobe antérieur gauche du cerveau. Bull Soc Anthropol Paris 2:235-238, 1861

7. Crivellato E, Ribatti D: Soul, mind, brain: Greek philosophy and the birth of neuroscience. Brain Res Bull 71:327-336, 2007

8. de Almeida AN: Unveiling the speechless brain: Edward C Séguin and the aphasia debate in 1868. J Neurol Neurosurg Psychiatry 87:783-784, 2016

9. de Almeida AN, Alho EJ, Teixeira MJ: Models of functional cerebral localization at the dawning of modern neurosurgery. World Neurosurg 81:436-440, 2014

10. De Witt Hamer PC, Robles SG, Zwinderman AH, Duffau H, Berger MS: Impact of intraoperative stimulation brain mapping on glioma surgery outcome: a meta-analysis. J Clin Oncol 30:2559-2565, 2012

11. DuanYu N, GuoJun Z, Liang Q, LiXin C, Tao Y, YongJie L: Surgery for perirolandic epilepsy: Epileptogenic cortex resection guided by chronic intracranial electroencephalography and electric cortical stimulation mapping. Clin Neurol Neurosurg 112:110-117, 2010
12. Eadie MJ: The role of focal epilepsy in the development of Jacksonian localization. J Hist Neurosci 18:262-282, 2009

13. Engdahl B, Leuthold AC, Tan HRM, Lewis SM, Winskowski AM, Dikel TN, et al: Post-traumatic stress disorder: a right temporal lobe syndrome? J Neural Eng 7:066005, 2010

14. Fishman RA: Books. Origins of neuroscience: A history of explorations into brain function. Ann Neurol 36:807, 2005

15. Goodrich JT: Models of functional cerebral localization at the dawning of modern neurosurgery-a perspective on these remarkable events. World Neurosurg 81:300-301, 2014

16. Harris LJ, Almerigi JB: Probing the human brain with stimulating electrodes: the story of Roberts Bartholow's (1874) experiment on Mary Rafferty. Brain Cogn 70:92-115, 2009

17. Hogan RE, English EA: Epilepsy and brain function: common ideas of Hughlings-Jackson and Wilder Penfield. Epilepsy Behav 24:311-313, 2012

18. Hogan RE, Kaiboriboon K: John Hughlings-Jackson's writings on the auditory aura and localization of the auditory cortex. Epilepsia 45:834-837, 2004

19. Horsley V: The Linacre Lecture on the function of the socalled motor area of the brain. BMJ 2:121-132, 1909

20. Irby GL (ed): A Companion to Science, Technology, and Medicine in Ancient Greece and Rome. West Sussex, UK: Wiley, 2016

21. Keles GE, Anderson B, Berger MS: The effect of extent of resection on time to tumor progression and survival in patients with glioblastoma multiforme of the cerebral hemisphere. Surg Neurol 52:371-379, 1999

22. Keles G, Lundin D, Lamborn K, Chang E: Intraoperative subcortical stimulation mapping for hemispheric perirolandic gliomas located within or adjacent to the descending motor pathways: evaluation of morbidity and assessment of functional outcome in 294 patients. J Neurosurg 100:369-375, 2004

23. Koehler PJ: Eduard Hitzig's experiences in the Franco-Prussian War (1870-1871): the case of Joseph Masseau. J Hist Neurosci 21:250-262, 2012

24. Ladino LD, Rizvi S, Téllez-Zenteno JF: The Montreal procedure: the legacy of the great Wilder Penfield. Epilepsy Behav 83:151-161, 2018

25. Leblanc R: Cushing, Penfield, and cortical stimulation. J Neurosurg 130:76-83, 2018

26. Levinson S: Return of the living dead. Re-reading Pierre Flourens' contributions to neurophysiology and literature. Prog Brain Res 205:149-172, 2013

27. Louis RG, Schiff D, Shaffrey ME: The first reported localisation and resection of a brain tumour. Lancet Oncol 11:302, 2010

28. Loukas M, Pennell C, Groat C, Tubbs RS, Cohen-Gadol AA: Korbinian Brodmann (1868-1918) and his contributions to mapping the cerebral cortex. Neurosurgery 68:6-11, 2011

29. Luzzatti C, Whitaker H: Jean-Baptiste Bouillaud, ClaudeFrançois Lallemand, and the role of the frontal lobe: location and mislocation of language in the early 19th century. Arch Neurol 58:1157-1162, 2001

30. McGirt MJ, Chaichana KL, Attenello FJ, Weingart JD, Than $\mathrm{K}$, Burger PC, et al: Extent of surgical resection is independently associated with survival in patients with hemispheric infiltrating low-grade gliomas. Neurosurgery 63:700-708, 2008

31. Morrell F, Whisler WW, Bleck TP: Multiple subpial transection: a new approach to the surgical treatment of focal epilepsy. J Neurosurg 70:231-239, 1989

32. Ojemann GA: Individual variability in cortical localization of language. J Neurosurg 50:164-169, 1979

33. Ojemann GA, Whitaker HA: Language localization and variability. Brain Lang 6:239-260, 1978

34. Ojemann JG, Miller JW, Silbergeld DL: Preserved function in brain invaded by tumor. Neurosurgery 39:253-259, 1996 
35. Orringer D, Lau D, Khatri S, Zamora-Berridi GJ, Zhang K, $\mathrm{Wu} \mathrm{C}$, et al: Extent of resection in patients with glioblastoma: limiting factors, perception of resectability, and effect on survival. J Neurosurg 117:851-859, 2012

36. Pendleton C, Zaidi HA, Chaichana KL, Raza SM, Carson BS, Cohen-Gadol AA, et al: Harvey Cushing's contributions to motor mapping: 1902-1912. Cortex 48:7-14, 2012

37. Penfield W, Roberts L: Speech and Brain Mechanisms. Princeton, NJ: Princeton University Press, 2014

38. Rubens AB, Mahowald MW, Hutton JT: Asymmetry of the lateral (sylvian) fissures in man. Neurology 26:620-624, 1976

39. Sanai N, Berger MS: Glioma extent of resection and its impact on patient outcome. Neurosurgery 62:753-764, 264266, 2008

40. Sanai N, Mirzadeh Z, Berger MS: Functional outcome after language mapping for glioma resection. $\mathbf{N}$ Engl J Med 358:18-27, 2008

41. Sandrone S, Zanin E: David Ferrier (1843-1928). J Neurol 261:1247-1248, 2014

42. Schijns OEMG, Hoogland G, Kubben PL, Koehler PJ: The start and development of epilepsy surgery in Europe: a historical review. Neurosurg Rev 38:447-461, 2015

43. Schramm J, Aliashkevich AF, Grunwald T: Multiple subpial transections: outcome and complications in 20 patients who did not undergo resection. J Neurosurg 97:39-47, 2002

44. Seitz R, Huang Y, Knorr U, Tellmann L, Herzog H: Largescale plasticity of the human motor cortex. Neuroreport 6:742-744, 1995

45. Skirboll S, Ojemann G, Berger M, Lettich E: Functional cortex and subcortical white matter located within gliomas. Neurosurgery 38:678-685, 1996

46. Smith JS, Chang EF, Lamborn KR, Chang SM, Prados MD, Cha S, et al: Role of extent of resection in the long-term outcome of low-grade hemispheric gliomas. J Clin Oncol 26:1338-1345, 2008
47. Spencer SS, Berg AT, Vickrey BG, Sperling MR, Bazil CW, Shinnar S, et al: Initial outcomes in the Multicenter Study of Epilepsy Surgery. Neurology 61:1680-1685, 2003

48. Stefanou MI: The footprints of neuroscience in Alexandria during the 3rd-century BC: Herophilus and Erasistratus. J Med Biogr [epub ahead of print], 2018

49. Steinberg DA: Cerebral localization in the nineteenth century - the birth of a science and its modern consequences. $\mathbf{J}$ Hist Neurosci 18:254-261, 2009

50. Sutherland-Foggio H: Developing the brain-early illustrations of cerebral cortex and its gyri. Pediatr Neurol 75:6-10, 2017

51. Todd R: On the pathology and treatment of convulsive diseases. London Med Gaz 8:661-671, 724-729, 766-772, 815-822, 837-846, 1849

52. Wada JA, Clarke R, Hamm A: Cerebral hemispheric asymmetry in humans. Cortical speech zones in 100 adults and 100 infant brains. Arch Neurol 32:239-246, 1975

\section{Disclosures}

The authors report no conflict of interest concerning the materials or methods used in this study or the findings specified in this paper.

\section{Author Contributions}

Conception and design: both authors. Acquisition of data: both authors. Analysis and interpretation of data: both authors. Drafting the article: both authors. Critically revising the article: both authors. Reviewed submitted version of manuscript: both authors. Approved the final version of the manuscript on behalf of both authors: Folzenlogen.

\section{Correspondence}

Zach Folzenlogen: University of Colorado School of Medicine, Aurora, CO. zach.folzenlogen@ucdenver.edu. 